\title{
Description of seven new species of seed beetles (Coleoptera Bruchidae) from Mediterranean basin and Africa
}

\author{
Marcello Franco Zampetti' \& Luciano Toma² \\ ${ }^{1}$ Via Attilio Staffa 4, 02022 Collalto Sabino, Rieti, Italy; e-mail: cecidios@gmail.com \\ ${ }^{2}$ Istituto Superiore di Sanità, Department of Infectious Diseases, Vector Borne Diseaes Unit., Viale Regina Elena 299,00161 Rome, \\ Italy; e-mail: luciano.toma@iss.it
}

\begin{abstract}
In this work, seven species of Bruchidae new to science are described. Five of these species belonging to the genus Bruchidius, namely Bruchidius horshensis n. sp., Bruchidius lekefensis n. sp., Bruchidius salinaensis n. sp., Bruchidius bcharreensis n. sp., Bruchidius samai n. sp. are from Mediterranean area. The remaining two new taxa, namely Spermophagus nicotrai $=$ Spermophagus sp. Zampetti, 1988 and Protobruchus (n. gen.) togoensis n. sp., are respectively from East Africa and from West Africa. Figures of the specimens and of respective genitalia are provided.
\end{abstract}

KEY WORDS Taxonomy; seed weevils; Bruchidae; Bruchidius; Spermophagus; Protobruchus.

Received 12.05.2020; accepted 20.06.2020; published online 30.06.2020

\section{INTRODUCTION}

The family Bruchidae Latreille, 1802 (Coleoptera) consists of about 1700 described species belonging to 60 genera and ranged in the subfamilies Amblycerinae, Bruchinae, Eubaptinae, Kytorhininae, Pachymerinae, and Rhaebinae (Southgate, 1979; Johnson \& Kingsolver, 1981). In this study, the Authors choose to keep the name of this group as a family according to Yus Ramos et al. (2007), despite the subsequent proposals introduced by Bouchard et al. (2011), in which Bruchidae have been formally downgraded to a subfamily within Chrysomelidae. This family occurs in the whole world but the poles and the deserts. Even if the majority of the species is limited to their natural ranges of distribution, a few of them became cosmopolitan because of the passive dispersion by human activities. In fact, also known as seed beetles, Bruchids feed on seeds of various plant families, but mainly the Fabaceae (= Leguminosae); several species became pests of legumes used as a food source for both people and livestock. In recent years, we have witnessed a significant proliferation of species that develop on ornamental plants in different parts of the world including Europe. In general, seed trade caused, and causes nowadays, the incoming of these species into Europe from other countries. Among many species passively imported, some of them become invasive establishing in natural habitats and integrating in European ecosystems, especially in the Mediterranean area (Yus-Ramos et al, 2014). In this work seven new species of Bruchidae from the Mediterranean area and Africa are described on the base on unique specimens evidently different from any other species known today. Five of these species belonging to the genus Bruchidius Schilsky, 1905, one to the genus Spermophagus Schoenherr, 1833 and one to the new genus Protobruchus are here described. Bruchidius horshensis n. sp., Bruchidius lekefensis n. sp., Bruchidius salinaensis n. sp., Bruchidius 
bcharréensis n. sp., and Bruchidius samai n. sp. are from the Mediterranean area, Spermophagus nicotrai $=$ Spermophagus sp. Zampetti 1988 is from East Africa and Protobruchus togoensis n. sp. is from West Africa. The descriptions have been carried out on unique specimens.

\section{MATERIAL AND METHODS}

Measurements of the specimens were taken as reported in Zampetti \& Ricci (2012). Dry genitalia were left in $\mathrm{KOH} 10-15 \%$ solution for 1 hour then cleaned in pure water and finally mounted on microscope slides in polyvinyl alcohol by the first author, according to Zampetti \& Ricci (2012).

Figures of the specimens and of respective genitalia are provided and have been taken from slide preparations. No data on distribution and host plants are available about these species as specimens were occasionally collected. Due to their Southern Mediterranean origin, of these specimens have been described on the base of what is reported in the references on the species from northern Africa, the Middle East and exotic seed beetles in general (Allard, 1868, Migliaccio \& Zampetti, 1989; Pic, 1902, 1903, 1904, 1913a, 1913b, 1913c; Ricci \& Zampetti, 2005, 2007). The description of the species through the type's examination is reported below.

The holotypes and paratypes of the new species here described are deposited at the National History Museum of London (UK) within the Zampetti collection.

\section{RESULTS}

\section{Systematics}

Ordo COLEOPTERA Linnaeus, 1758

Subordo POLYPHAGA Emery, 1886

Superfamilia CHRYSOMELOIDEA Latreille, 1802

Familia BRUCHIDAE Latreille, 1802

Genus Bruchidius Schilsky, 1905

Bruchidius horshensis n. sp. - Figs. 1-3 http://zoobank.org/4fa2f599-a1be-4ea9-8df1$66174 d c 832$ bc

ExAmined material. Types examined. Female holotype. Liban, Zgharta, Horsh Ehden, Nat. Res.,
$1700 \mathrm{~m}$ above s.1., 8/16.VI.1999, G. Sama legit; 2 female paratypes, same data of the holotype.

DesCription OF THE HOLOTYPE. Female, habitus as in figures 1 and 2. Length: $5.7 \mathrm{~mm}$, width $2.5 \mathrm{~mm}$. Body elongated and oval, and completely black. Oval body extremely elongated with greater width and main convexity just before the middle part of the body at about $1 / 3$ from the base of elytra. The insect is black with the exception of the second antennal segment which is dark red. It is covered by an ashy- grey uniform pubescence over the whole body but a long tuft of light gray bristles is present across the middle part and at the sides of the pygidium.

The head has the clypeus a quarter longer than wide, the forehead-clypeus edge is present but not very engraved, the frontal carena is complete, evident and translucent with no narrowing behind the eyes. The markings are deep and the pubescence is thin of ashy color, denser on the clypeus and on its sides. The antennae go just over the base of the elytra and are serrated starting from the fifth article. Article 2 is sub-triangular as long as it is wide, the 3rd is almost cylindrical, about 1.5 times longer than wide and longer than the 2 nd but of equal width. The 4th antennal segment is slightly longer and a little wider than the previous one; the 5 th is a little longer and wider than the 4th, about 1.5 times the width. The antennal items from the 5 th to the 10th are sub-triangular decreasing in length but of constant width so that the 10th results having the same width and length.

The prothorax has a conic shape with straight back angles, just longer than wide, uniformly convex although there are two evident depressed areas, one to every side of the basal lobe. It presents slightly sinuous sides, and the base is also straight with a protruding central part. The basal edge is absent while the apical one is present but incomplete in the upper part. The pubescence is light and uniform with a tuft of bristles in the middle of the base; the markings are uniform and coarse. The scutellum is small and has a semi-triangular shape, as wide as long, covered by a light, ashy-white and uniform pubescence presenting markings that are similar to the prothorax.

The elytra are rectangular, roughly 1.5 times longer than wide, slightly convex, and there are no tubercles at the base. The markings are thin and light thus not appearing very visible whilst the pubescence is so thick that it tends to hide the un- 
derlying tegument, especially in the apical part whilst appearing thinner on the humeri.

The legs present a strong and clearly visible tooth on the inner part of the back femurs. The tibias are straight, with the back ones ending with two short black thorns one longer than the other. The total length of the back tarsi is slightly inferior to the length of the respective tibiae.

The pygidium is flat, with the exception of a longitudinal central convexity from the base to the apex, slightly tilted in comparison to the surface, about 2 times longer than wide at the base presenting no curving at the apex. The markings are very fine and shallow thus presenting a somewhat wrinkled appearance on the surface. The greyish pubescence is rather uniform but thicker in the center of the basal part, on the sides and along the central convexity. Female genital typical of the genus Bruchidius (Fig. 3).

VARIABILITY. Female paratypes do not have substantial morphological differences with the described holotype. Male: unknown.

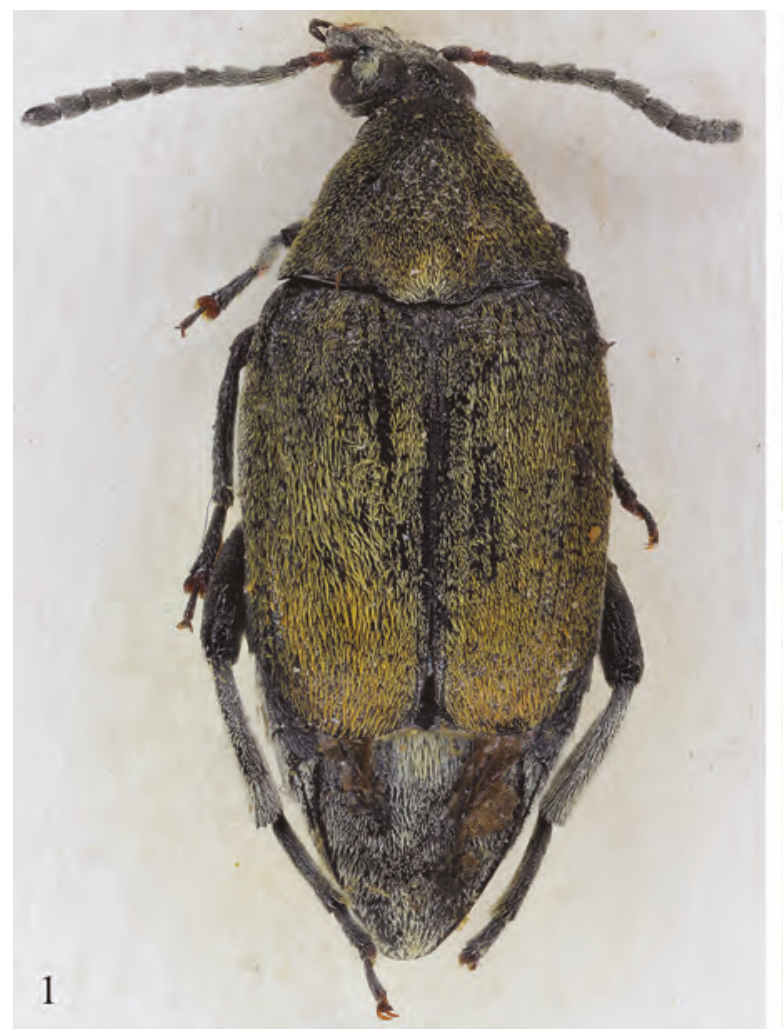

DistRIBUTION. This new species is known only from the locus typicus: Liban, Zgharta, Horsh Ehden Natural Reserve, 1700 m above s.l., 8/16.VI.99. G. Sama leg.

DifFERENTIAL DiAgNosis. The filiform antennae, the elongated body shape and in particular the pygidium together with the tomentosity of the elytra are characters in common with Bruchidius cinerascens (Gyllenhal, 1833) and to the Bruchidius monstrosicornis (Pic, 1904).

Bruchidius lekefensis n. sp. - Figs. 4-6 http://zoobank.org/6830cde4-de76-465b-83d9$975 \mathrm{e} 3 \mathrm{f} 67 \mathrm{a} 77 \mathrm{e}$

EXAmined Material. Holotype male. Tunisia, $\mathrm{km} 25$ Le Kef-Teboursouk road, 400-500 m above s.l., S. Zoia legit, 18.IV.1993.

DESCRIPTION OF THE HOLOTYPE. Male's habitus as shown in figures 4 and 5 . Lenght: $3.8 \mathrm{~mm}$, maximum width: $1.8 \mathrm{~mm}$. Short and oval body. Completely
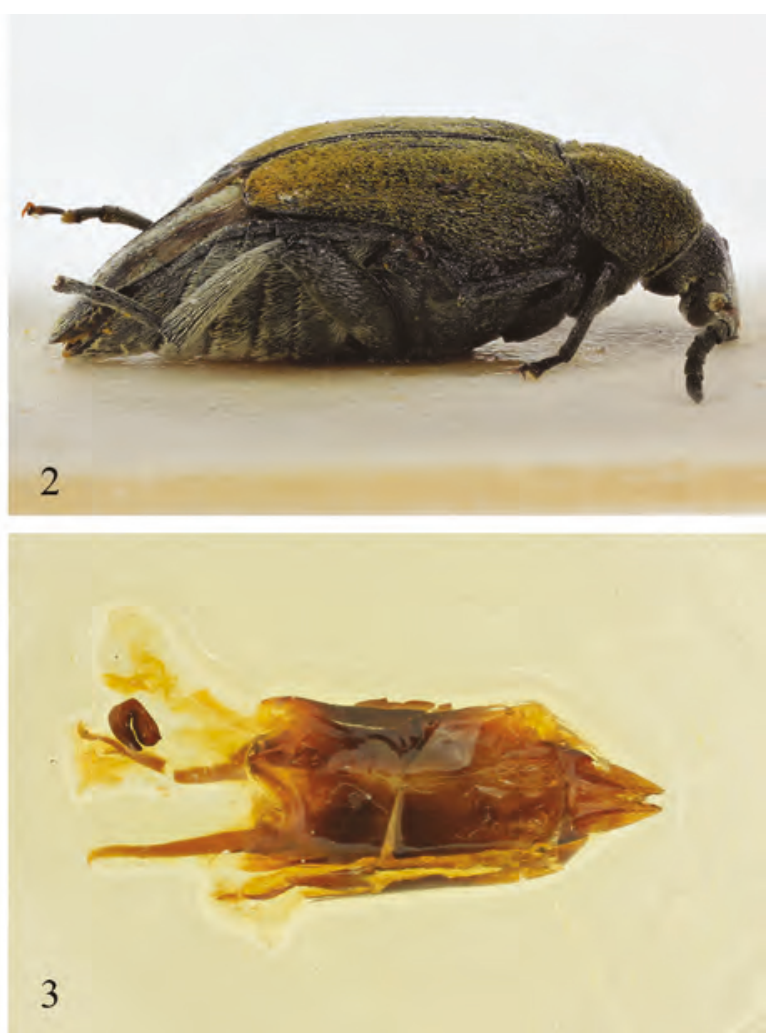

Figures 1-3. Bruchidius horshensis. Fig. 1: habitus of the type female, dorsal view.

Fig. 2: habitus of the type female, lateral view. Fig. 3: genitalia of the female. 
black body. Oval body, elongated meaning wider in the middle and the maximum convexity from $1 / 3$ from the base of the elytra. Species of black color with the exception of the articles 1-3 of the antennae and the legs partially red. It is covered by a very light ashy-grey pubescence almost uniform over the whole body with the exception of the pygidium which is denser thus hiding the underlying tegument.

The head with the clypeus slightly longer than wider with the line of the forehead-clypeus forming a distinctive $\mathrm{V}$ shape. The frontal carena is complete and shiny, well evident. No narrowing behind the eyes. The markings are deep and coarse, with a thin ashy-gray pubescence. The antennae go beyond the base of the elytra but are shorter than half of the body; they are serrated starting from the 4th article. The 2 nd article is spherical in shape having the same length and width; the 3 rd item is triangular about 1.5 longer than wider, and 1.5 times longer than the $2 \mathrm{nd}$. The 4 th article is roughly $1 / 3$ longer and wider than the previous. The articles from the 5 th to the 10 th have a sub-triangular shape constant in length and width, 1.5 times longer than wider.

Conic prothorax with sharp back angles, 1.3 times wider than longer and uniformly convex, with two sunken areas in front of the back angles. It portrays sinuous edges, the base is straight with a slightly protruding central part. The apical edge is complete and distinct whilst the basal part is just outlined. The pubescence is thin, uniform and of ashy-gray color, with a lock of bristles in front of the scutellum. The markings are uniform and deep, as on the head. The scutellum has the same measurements in length and width and is covered by a dense ash-white uniform pubescence.

Rectangular elytra, with almost parallel sides, about 1.5 times longer than wider, almost convex. There are no tubercles at the base. The markings are uniform and clear composed of small dots and the pubescence is uniform and thin. The humeri have no hair. First and second legs are of a red brown color but the femurs are darkened at the basal part. Back femurs have a dwarfish tooth, just
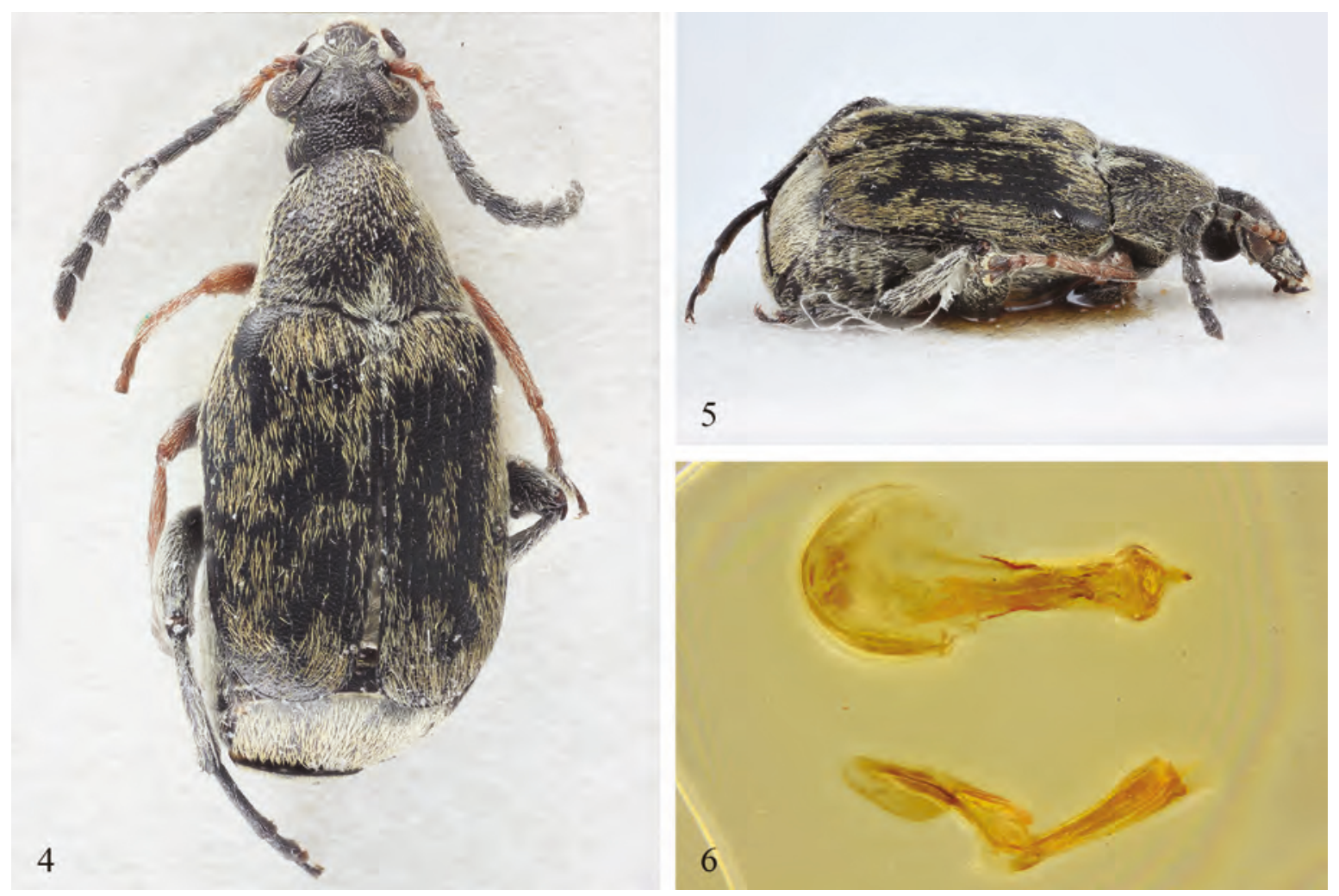

Figures 4-6. Bruchidius lekefensis. Fig. 4: habitus of the type male, dorsal view.

Fig. 5: habitus of the type male, lateral view. Fig. 6: aedeagus. 
visible, on the inner side. The tibiae are straight, the back ones ending with some black thorns of the same length.

The pygidium is very reclined, almost perpendicular, slightly longer than wider; rather convex with a curved apex. The pubescence and the markings are both fine, dense and uniform.

The aedeagus shows cylindrical median lobe with linear and parallel sides. The apex is widened terminating with a small but well visible thorn. The paramers have a linear aspect expanding in width. The lobes are turned toward the inside having bristles in the apical part. The basal part holds the paramers together and it is composed by two segments fused around the median lobe that are extended with an odd piece (Fig. 6).

VARIABILITY. Female unknown.

Distribution. This new species is known only from the locus typicus: Tunisia, km 25 Le KefTeboursouk road.

DifFERENTIAL DIAGNOSIS. although it presents

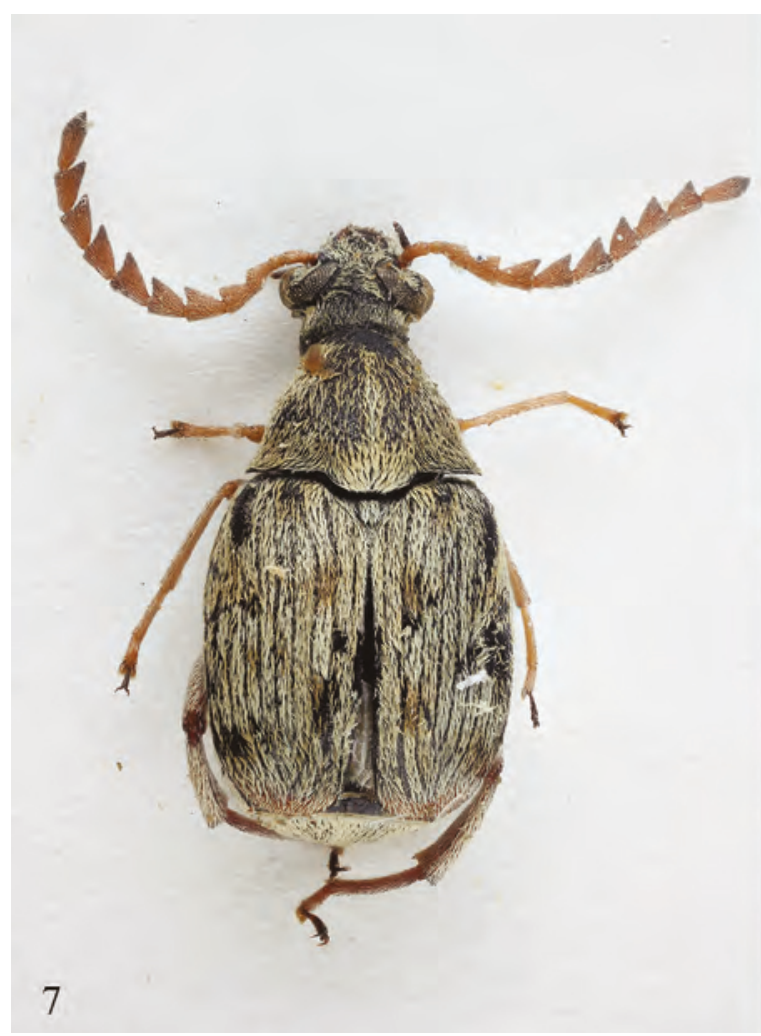

flat elytrae, this bruchid appear very close to Bruchidius varipictus (Motschulsky, 1873).

Bruchidius salinaensis n. sp. - Figs. 7-9 http://zoobank.org/664d6b61-77fa-4bbc-8f17759e98403d06

Examined Material. Holotype male. Salina, Lingua, Sicily, Italy, P. Lo Cascio \& F. Grita legit, 10.V.2009.

DESCRIPTION OF THE HOLOTYPE. Male, habitus as in figures 7 and 8 . Length: $3.5 \mathrm{~mm}$; width: $1.7 \mathrm{~mm}$; the shape of the body is short and oval, totally black in color. Oval elongated body with the maximum width beyond the middle of the body and the maximum convexity at $1 / 3$ from the base of the elytra. The insect is black with the exception of the antennae and the legs which are dark red. It is covered by an ashy-gray uniform pubescence on the whole body but two locks of light brown bristles are noticed on the third gap of each elytra, one in front and the other one behind its middle. The head with

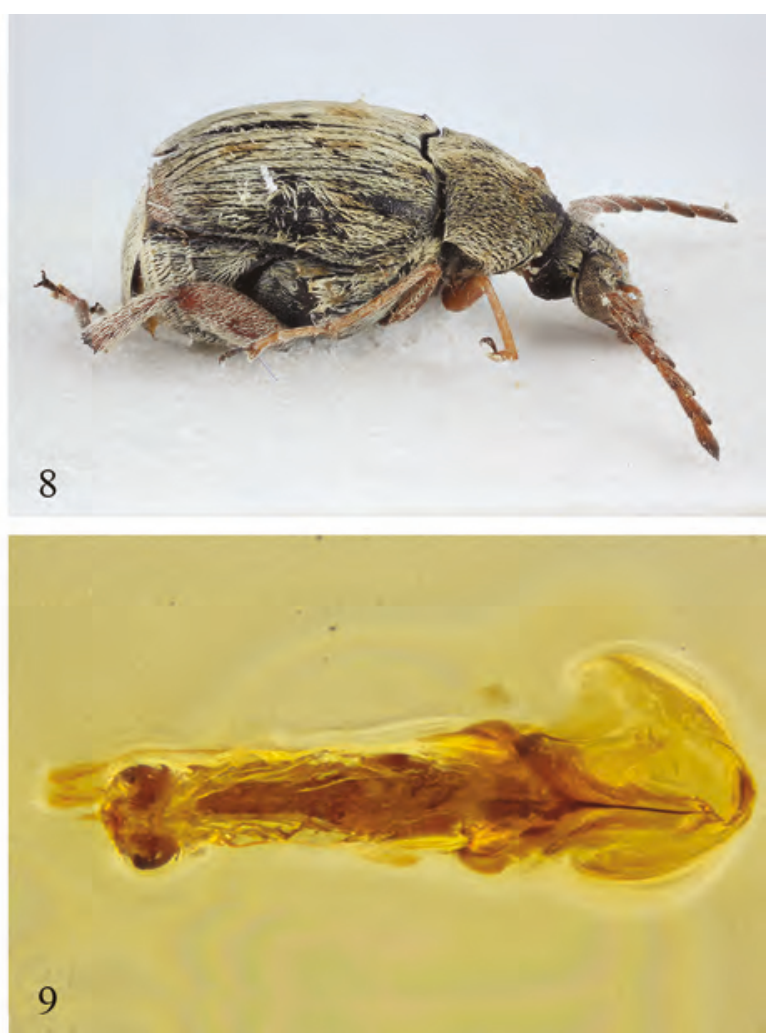

Figures 7-9. Bruchidius salinaensis. Fig. 7: habitus of the type male, dorsal view.

Fig. 8: habitus of the type male, lateral view. Fig. 9: aedeagus. 
the clypeus slightly longer than wider, foreheadclypeus edge present but hard to see, frontal carena complete, very clear with no narrowing behind the eyes. The markings are deep and the pubescence is sparse and is ashy-gray.

The antennae exceed the base of the elytra and are serrated starting from the fourth article. The 2 nd article is of spherical shape having the same measurements in length and in width; the 3rd is triangular but the upper side is not perpendicular to the axis but tilted toward the outside; it is a little longer than wider about twice the length of the 2 nd. The 4th segment is slightly longer and wider than the previous. Antennal segments from the 5th to the 10th are subtriangular and constant in length. The width from the 5 th to the 7 th antennal segments expands while the 8 th to the 10 th decreases.

The prothorax is of conic shape with pointed back angles, 1.3 times wider than longer resulting uniformly convex although there are some hollowed areas in the middle and at the sides of the basal lobe. It portrays sinuous sides, the base is straight with a very protruding central part. The basal and the apical edges are complete and distinct. The pubescence is dense and varied, more visible and off-white at the base and along a central longitudinal line. The markings are uniform and less pronounced than those on the head. The scutellum is the same in width and length, covered by a thick ashy-white uniform pubescence.

The elytra is square shaped, slightly longer than wider, and just a little convex. There are two tubercles at the base of the 3rd and 4th striae that are very close to each other giving the impression of being one tubercle. The markings are clear, composed of small dots and the pubescence is variegated, dense in some areas. A few dots of brown bristles on two transverse sections are visible, four on the anterior section at about $1 / 3$ from the base and a further four dots on the posterior section at about $1 / 3$ from the apex. The humeri have no hair. Legs have a small tooth on the inner part of the back femurs. The tibiae are straight, the back ones terminate with two short black thorns one longer than the other. The 1st segment of the tarsus of the first and second legs has no thorns. The pygidium is very tilted, virtually perpendicular to the surface, about 1.3 times longer than wider, a little convex and with a slightly curved apex. Both the pubescence and the markings are very thin and uniform.
Aedeagus: cylindrical median lobe with linear edges and the apex with two arc-shaped layers which, seen in section, form a heart shape. At the apex a small thorn is well visible: from the side, the median lobe appears curved in the sub-apical area due to the presence of the two arc-shaped layers. The paramers have linear edges and have the same width along the whole length. The lobes are turned towards the inside with bristles in the sub-apical part. From the side one can see an arc-shaped layer in the middle of the lobe of the paramers. The basal piece holds the paramers united and consists of two segments joined around the median lobe that continue with an odd-piece toward the apex. Spiculum gastrale with two segments forming a "V" shape and the third segment originating from their point of intersection and being just a little shorter (Fig. 9).

VARIABILITY. Female unknown.

DistRIBUTION. This new species is known only from the locus typicus: Salina, Lingua, Aeolian Islands, Sicily, Italy.

DifFERENTIAL DIAGNOSIS. This bruchid shows at the same time the elytra with tubercles at the base (a common character among black bruchids with scattered dense gray pubescence) and legs and elytrae red in color. These characters together with the 3rd antennal segment deformed triangle shaped, make this species very similar to Bruchidius martinezi (Alard, 1868).

Bruchidius bcharreensis n. sp. - Figs. 10, 11 http://zoobank.org/44b94540-f865-49bd-8bc0$85 \mathrm{f} 7 \mathrm{f} 68 \mathrm{a} 1 \mathrm{e} 90$

EXAMINED MATERIAL. Holotype female. Liban, caza Bcharré, Cédres de Bcharré, 1950 m above s.l., P. Brignoli legit, 3/5.VI.1972.

DESCRIPTION OF THE HOLOTYPE. Habitus of the female as in figures 10 and 11. Length $2.5 \mathrm{~mm}$, maximum width $1.3 \mathrm{~mm}$; it has an oval shape, slightly elongated, with a completely black body apart from the legs and the antennae that are partially red. The female body is slightly elongated portraying the maximum width being behind the half-way part of the body in the middle of the elytra. This insect is black with some exceptions described here as follows. The first antennal segment is red becoming darker red in the upper part; the segments $2-4$ are 
red as well as the legs even if in the third pair the femurs are darker red in the basal part. Tarsi are also brownish red. The body is covered by an ashy-grey uniform pubescence over the whole body apart from a lock of light grey bristles at the base of the thorax. The head with the clypeus has roughly the same width and length, the forehead-clypeus edge is present but only lightly engraved, the frontal carena is complete, evident, translucent and has no narrowing behind the eyes. The markings are not very deep and the pubescence is almost absent apart from the area between the eyes where it is very sparse and denser on the clypeus and on its lateral sides, it is an ashy color. The antennae begin from the base of the elytra and are serrated starting from the fifth segment. The 2nd segment is square shaped as long as wide; the 3rd segment is cylindrical and is fairly longer than the 2 nd segment but has the same width. The 4 th segment is almost double the length and wider than the previous and the 5th segment is a little longer than the 4th, as long as is wide. The antennal segments from the 6th to the 10th are subtriangular shaped and constant in length and in width, so that the 10th segment appears as long as it is wide.

The prothorax is conical with straight back angles, slightly wider that longer, uniformly convex. It presents slightly sinuous sides, the base is also straight with the central part just a little protruding. The basal edge, as in its apical part as well as in its basal part, is complete. The pubescence is light and smooth with a large lock of bristles in the middle of the base; the markings are uniform and coarse. The scutellum is small, square shaped, as wide as long, covered by a light ashy-white pubescence and with markings that are similar to the ones on the prothorax.

The elytra are rectangular, about 1.3 times longer than wider, and a little convex. One tubercle is present at the base of the fourth striae. The markings are sparse and light thus, not very visible, and the pubescence is so dense that it tends to hide the underlying tegument with the exception of the humeri where it is a little sparser. The legs have no tooth on the inside side of the rear femurs. The tibiae are straight, with the back ones ending with two short black thorns one longer and stronger than the other. The total length of the back tarsi is the same length of the respective tibiae.

The pygidium is slightly convex, uniform from the base to the top, very tilted compared to the surface, as long as wide. The markings are very fine and not very pronounced. The greyish pubescence is uniform, denser than the rest of the body similar to the one located at the base of the thorax. Female genital typical of the genus Bruchidius.

\section{VARIABILITY. Male unknown.}

DistRIBUTION. This new species is known only from the locus typicus: Liban, caza Bcharré, Cédres de Bcharré, m 1950, - 3/5.VI.72. P. Brignoli leg.
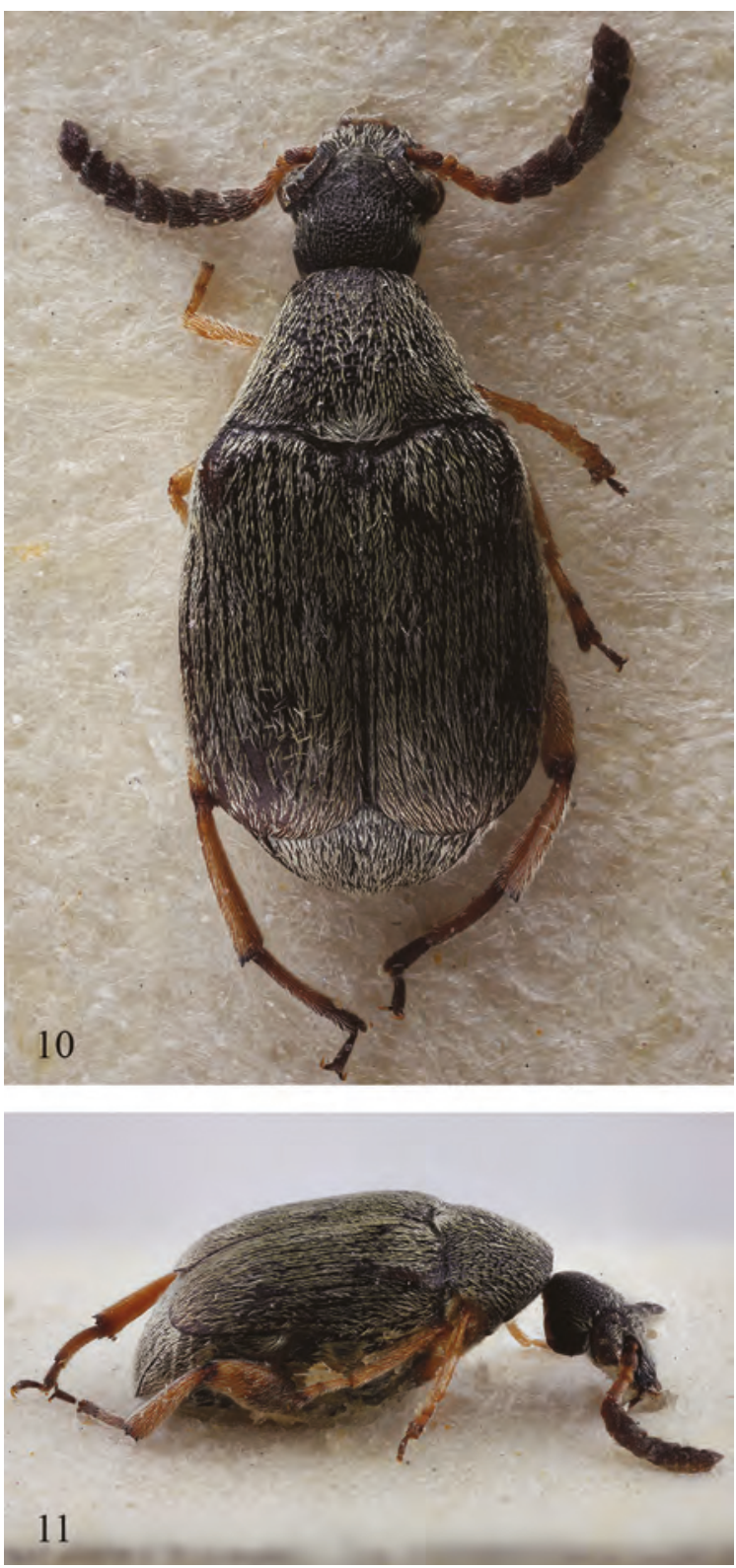

Figures 10, 11. Bruchidius bcharreensis. Fig. 10: habitus of the type female, dorsal view. Fig. 11: habitus of the type female, lateral view. 
DifFERENTIAL DIAGNOSIS. The first antennal segments of the body shape and structure of the legs, make this species look like Bruchidius nanus (Germar, 1824) and more widely the nanus-tuberculatus-obscuripes group.

Bruchidius samai n. sp. - Figs. 12-14 http://zoobank.org/4f6bb38c-2ed6-4437-88f9$604 \mathrm{f} 42 \mathrm{e} 71355$

EXAMINED MATERIAL. Holotypus male. Turkey, vil Mersin, $8 \mathrm{~km}$ North Tarsus foreward Çamlayla, G. Sama legit, 02.VI.1981.

DESCRIPTION OF THE HOLOTYPE. Habitus of the male as in figures 12 and 13. Length: mm 2.5; width: mm 1.2; thus, the body appears short and oval and totally black, with the maximum width displayed behind the middle of the body and the maximum convexity at the middle of the elytra. The insect is covered all over by a very thin ashy-grey, almost uniform pubescence. The head with the clypeus is slightly longer than wider, the edge of the forehead-clypeus displays a very evident " $\Lambda$ " shape and the frontal carena is complete and evident; there is no constriction behind the eyes. The markings are deep, rough and coarse as seen throughout the rest of the body. The antennae, with the 4th and 10th segments, are completely open and go beyond the base of the elytra; they are serrated starting from the fourth segment. The 2 nd segment has a spherical shape as long as wide; the 3rd segment has a triangular shape and it is almost twice longer and wider than the 2 nd segment. The 4 th segment is respectively 1.5 and 1.7 times longer and wider than the previous segment. The antennal segments from the 5 th to the 10th have a subtriangular shape and are constant in length; the width of the segments from the 5 th to the 7 th increase while the width of the segments from the 8 th to 10 th decrease.

The prothorax presents a cone shape with sharp back angles, just longer than wider and uniformly convex from the base to the top; it displays sinuous lateral sides, also the base is straight with the central part slightly protruding. The basal edge is absent
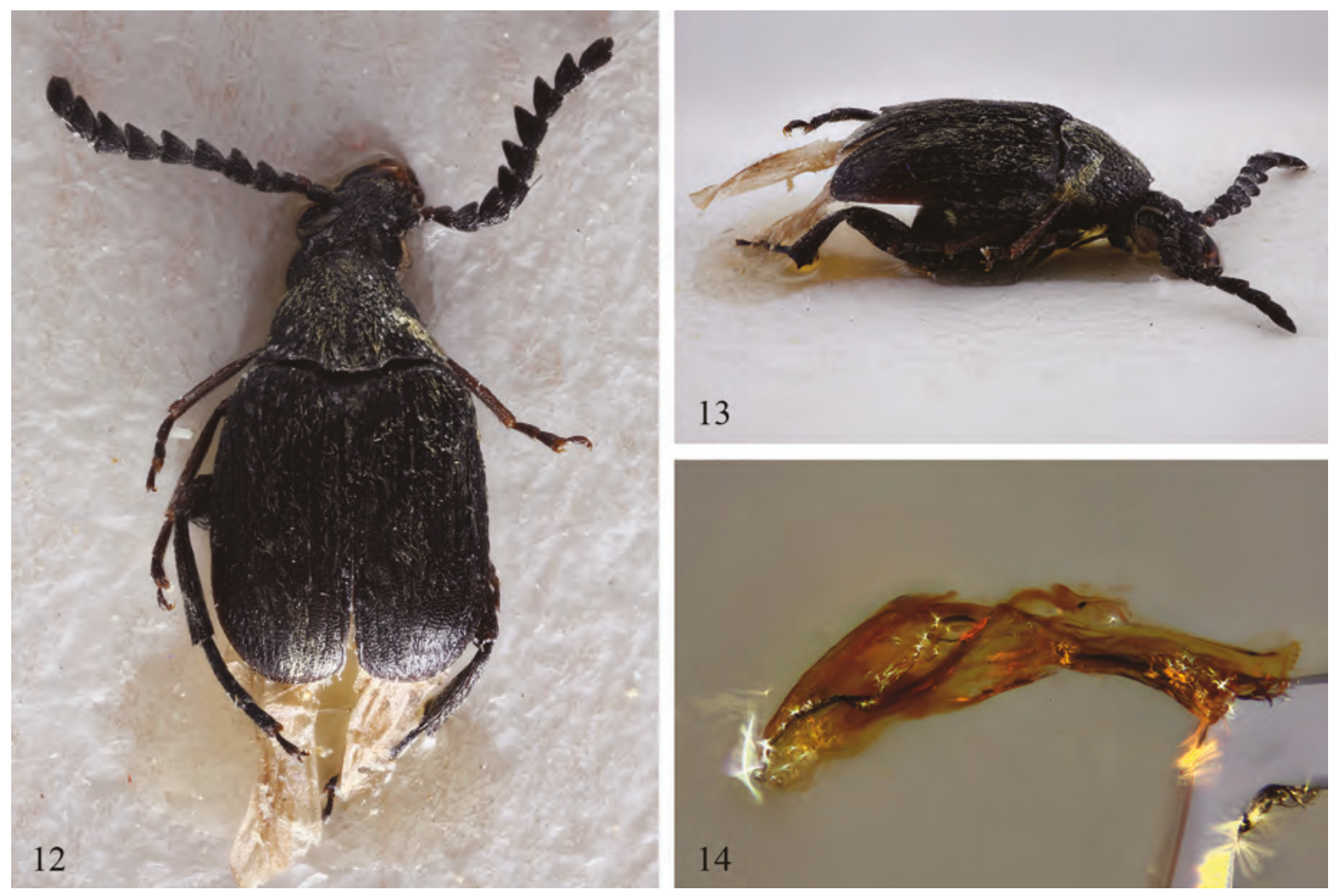

Figures 12-14. Bruchidius samai. Fig. 12: habitus of the type male, dorsal view.

Fig. 13: habitus of the type male, lateral view. Fig. 14: median lobe of the aedeagus. 
while the apical one is incomplete and so only present in the middle part. The markings are uniform and less pronounced than on the head. The scutellum is as long as wide.

The elytra are sub-square shaped, 1.3 times longer than wider, and a little convex. The small dotted markings are simple and uniform. The humeri are bare only in the upper part. The legs have no tooth on the inside of the back femurs. It displays straight tibias, with the back ones ending with two very short black thorns a little visible and only one of them is longer than the other. The back tarsi are a little longer than the tibia. The abdomen of this specimen is unfortunately lost.

Aedeagus: median lobe is progressively enlarged from the articulation of the paramers up to the apical part. The paramers display a linear edge and the apex terminates in a sharp triangular tip; a small tip is evident at the apex. From the side the median lobe appears curved at the top part. The paramers have linear edges and have the same width along the whole length. The lobes are turned toward the inside and endowed with bristles in the upper part. The basal part holds the paramers together and consists of two segments gathered around the median lobe which continue to the apex with an uneven piece (Fig. 14).

VARIABILITY. Female unknown.

Distribution. This new species is known only from the locus typicus: Turkey, vil Mersin, $8 \mathrm{~km}$ North Tarsus foreward Çamlayla.

DifFERENTIAL DIAGNOSIS. The characters of this holotype seem to set it very close to Bruchidius reitteri Schilsky, 1906 to which two other species can be related: Bruchidius richteri Ter-Minasyan, 1954 and Bruchidius migliaccioi Zampetti, 1998.

Genus Spermophagus Schoenherr, 1833

Spermophagus nicotrai n. sp.- Figs. 15, 16 = Spermophagus sp. Zampetti, 1988

http://zoobank.org/e07a11ef-bf2c-4754-b7cb$666 \mathrm{a} 62 \mathrm{e} 6408 \mathrm{c}$

EXAmined MATERIAL. Holotype female. Somalia, Afgoi, Nicotra legit, VII/XII.1937.

DESCRIPTION OF THE HOLOTYPE. Female, habitus as in figures 15 and 16 . Length $2.7 \mathrm{~mm}$, maximum length $1.66 \mathrm{~mm}$; the shape of the body is short and oval. It is totally black with the exception of the terminal thorn on the back tibia that is a brown-red color. Short oval body, with the maximum width and the maximum convexity in the middle part of the body. It is a black insect covered by a very thin ashygrey pubescence, barely visible and scattered. The head is a semicircular form situated behind the eyes and strongly convex. The clypeus is roughly 1.5
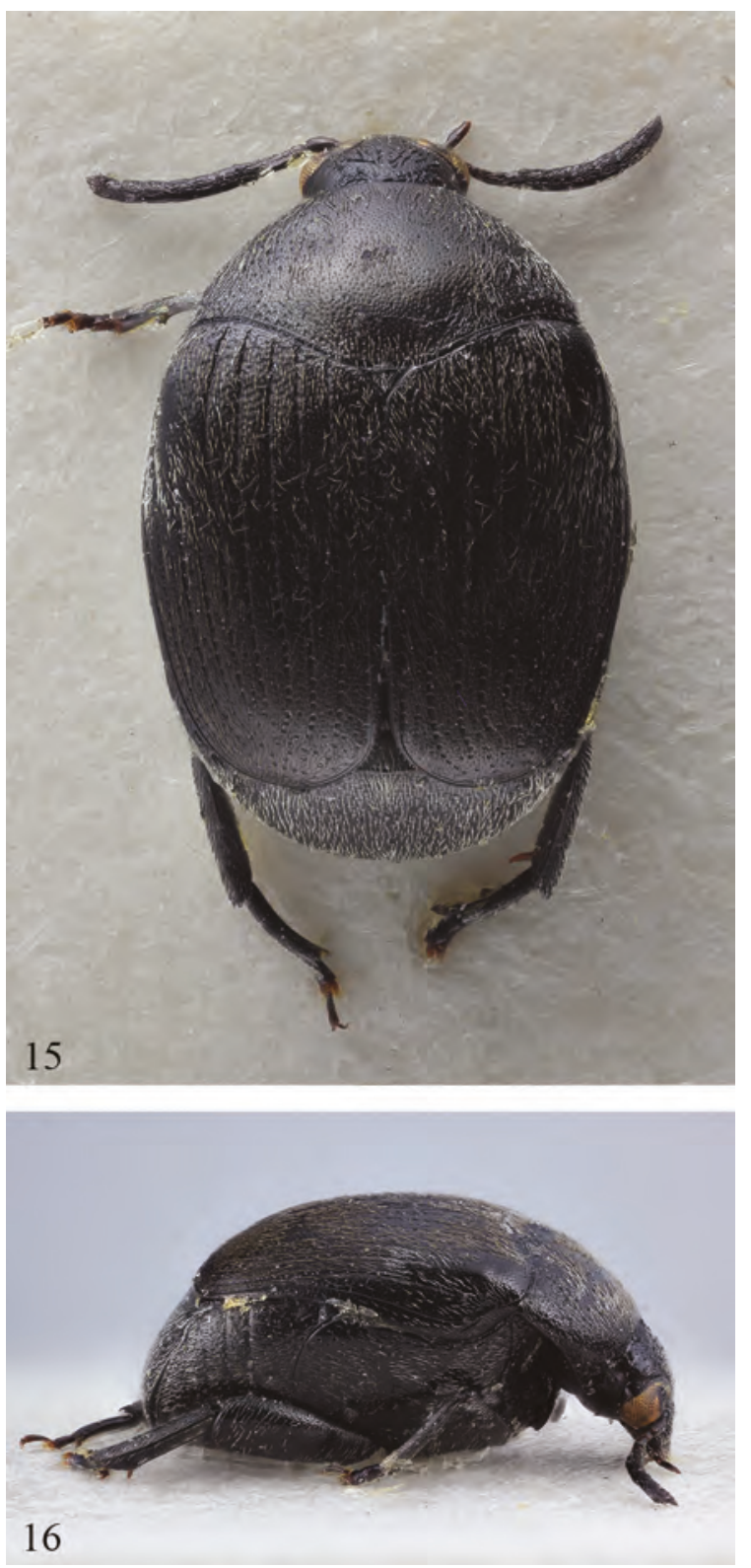

Figures 15, 16. Spermophagus nicotrai. Fig. 15: habitus of the type female, dorsal view; Fig. 16: habitus of the type female, lateral view. 
wider than longer. The forehead-clypeus edge is straight. The eyes are normally convex which is a typical feature of the genus. The markings are thin, dense and uniform. The antennae arrive just at the middle of the thorax; thread-like and with segments that are slightly enlarged starting from the 5th segment. The 2nd antennal segment is small, sub-spherical, slightly longer than wider; the $3 \mathrm{rd}$ segment is 1.3 times longer than the $2 \mathrm{nd}$; the 4 th segment is slightly shorter than the previous one and almost of the same width. The 5 th segment is shaped like a trapezoid and it is 1.2 times wider than the previous, almost as long as it is wide. The segments from the 6th to 10th are sub-rectangular, constant in length and width, almost 1.2 times longer than wider.

The prothorax is shaped like a bell with its sides converging forward forming an arc shape from the base so that the back angles result as right angles; it is 1.8 times wider than longer. The apical and the basal edges are complete. The pronotum is uniformly convex in both directions and its base is serrated. The markings are thin composed of average-size dots like the ones on the head. The scutellum is a triangular shape with the same width and length.

The elytra are about 1.5 times longer than wider portraying their maximum convexity in both directions, in the apical half and almost flat in the basal half. The humeri are protuberant, with thin markings, shallow and uniform on the inter-striae and with clearly larger dots on the striae. All the striae are complete with the exception of the 7th and 8th which are interrupted just before the humeri, while the 9th stops at their side. The first and the second pair of legs are thin while the third pair have little swollen femurs. The tibiae are slightly enlarged and a little compressed ending with one (the presence of only one mobile thorn, since in the other tibia the mobile thorns are absent, leads to suppose that during the preparation of the specimen the mobile thorns were broken) long, strong red moveable thorn, one stronger black thorn and three smaller ones all attached on the upper side.

The pygidium is a little tilted with a curved apex. Its width is 1.4 times the length. The markings are uniform and made up of fairly large dots. The ovipositor was not extracted.

VARIABILITY. Male unknown.

Distribution. This new species is known only from the locus typicus: Somalia, Afgoi.
DifFERENTIAL DIAGNOSIS. This new species is somewhat similar to Spermophagus somalicus, which however has two red spines at the end of the tibia (Decelle, 1979), a character that is not observed in this holotype.

Protobruchus nov. gen.

http://zoobank.org/02c6a0ee-7f1d-4b85-90ce$1 \mathrm{fdbf} 4 \mathrm{c} 66901$

Type species: Protobruchus togoensis n. sp.

This new genus is characterized by the combination of the following features:

- head moderately lengthened, borderless eyes for $3 / 5$, central carena present and clearly visible, shiny and complete;

- normal antennae in the male, not combed nor clasped;

- pronotum without lateral edge;

- short, triangular protosternal process separating the protocoxae throughout the whole length;

- metasternum strongly angled from the profile;

- back femurs are slightly thickened and the dorsal carena has no teeth;

- two preapical thorns are present: a strong one typical of the species and an inside thorn, having the same dimensions, thinner and sharper but definitely bigger, typical of the genus Bruchidius; both thorns are the same length; the position of these thorns recalls the genus Callosobruchus but it is distinguished by the absence of the other characteristics.

- back tibia is straight without a carena and without terminal thorns;

- first posterior tarsus roughly $2 / 3$ in length of the respective tibia and about 5 times the length of the tarsus.

Protobruchus togoensis n. sp. - Figs. 17-19

http://zoobank.org/ea5da563-adbb-4b9c-8913$8 \mathrm{a} 2$ cebd9adc9

EXamined material. Holotype male. Togo, Sokodé, $400 \mathrm{~m}$ above s.l., I.1991, Melandri legit.

DESCRIPTION OF THE HOLOTYPE. Male, habitus as in the figures 17 and 18 . Length $5.8 \mathrm{~mm}$, maximum width $2.7 \mathrm{~mm}$; thus, the insect results having an elongated and oval shape. The body is uniformly red-brown with the exception of the head being slightly darker. It is covered by a tawny clear uni- 
form pubescence over the whole body apart from two areas, the pygidium and a lock of thick bristles towards the scutellum, that tends to hide the underlying tegument. The head has the clypeus slightly longer than wider and the forehead-clypeus edge is arc-shaped and clearly visible. The frontal carena is robust, complete and shiny. The narrowing behind the eyes is present but not evident. The dotting patterns are marked but not very big. The antennae go beyond the base of the elytra but are shorter than half of the body: they are slightly serrated beginning from the fourth article. The second antennal segment has a spherical shape as long as it is wide; the third is triangular, narrow and elongated and it is 1.7 times longer than wider and longer about twice the second segment. The 4th antennal segment is just longer and a little shorter than the third. The antennal segments from the 5 th to the 10th are subtriangular and fairly constant in length and width, as long as wide with the exception of the 10th that is slightly narrower than the previous ones and is $1 / 4$ longer than wider. The base of each segment from the 5 th to the 10 th increases in width, so the shape of the antennal segments changes from triangular to rectangular.

The prothorax is conic shaped with sharp back angles, 1.4 longer than wider, uniformly convex; it portrays upright sides slightly curved in the middle, the base is also straight with the central part slightly curved. The apical edge is complete while the basal one is absent. The markings are not uniform as big dots alternate with smaller dots, however, it is visibly marked as on the head. Scutellum is sub-square shaped roughly wide as it is long, covered by a dense marking similar to the one on the prothorax.

The elytra are rectangular with almost parallel sides, about 1.2 times longer than wider and flat in the central part. The striae are deep and complete, the 9 th and 10th are joined at the base of the elytra. The markings are uniform as on the prothorax. Back femurs slightly thickened; two apical thorns are present, one external and robust and one internal thinner and sharp; both thorns are of the same length.

The pygidium is very inclined, practically per-
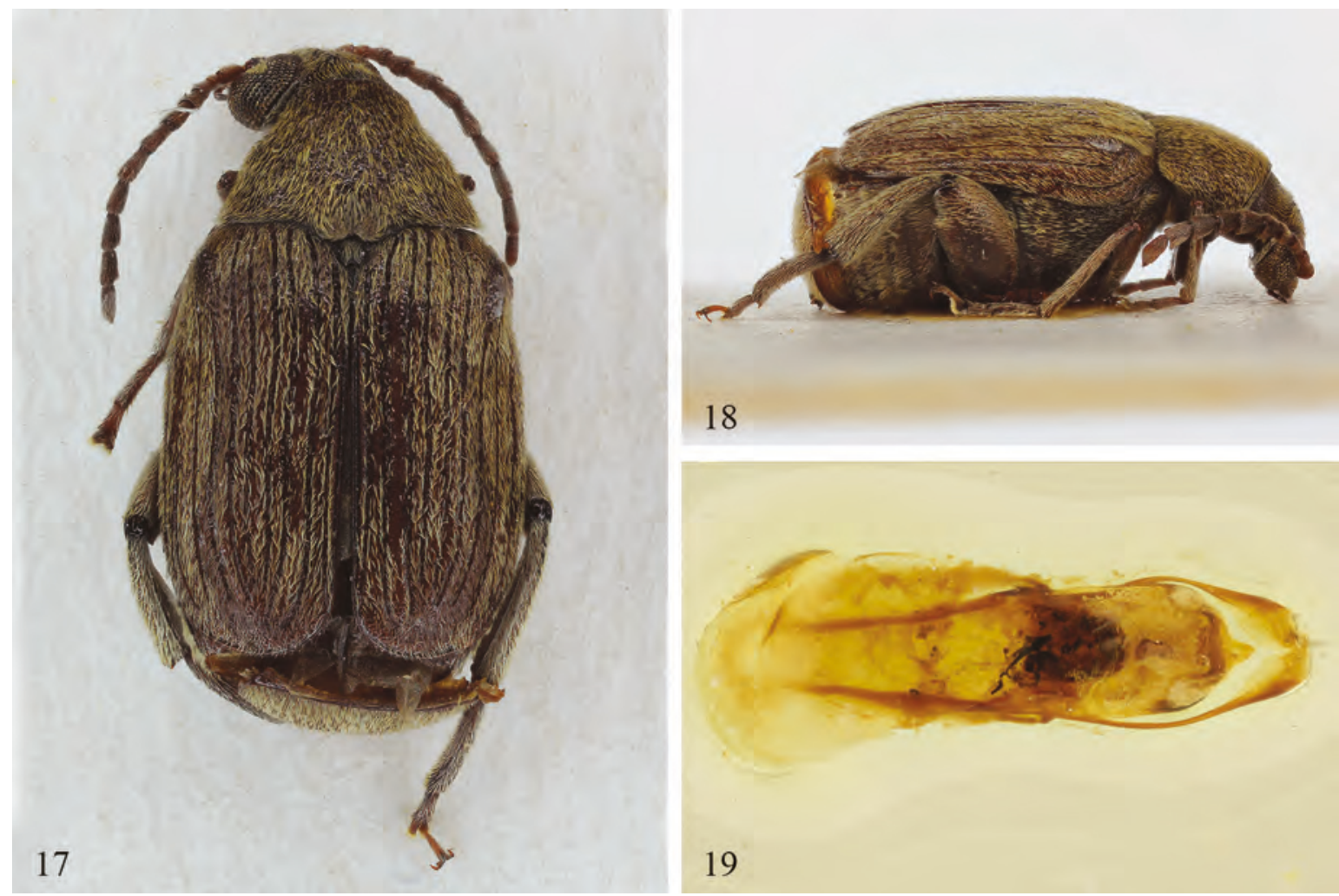

Figures 17-19. Protobruchus togoensis. Fig. 17: habitus of the type male, dorsal view. Fig. 18: habitus of the type male, lateral view. Fig. 19: aedeagus. 
pendicular, longer than wider, convex and with a curved apex. The markings are the same as in the other parts of the body but less emphasized.

Aedeagus: median lobe is oval shaped with arched edges. The apex is thickset, enlarged and ending with a small but evident thorn. The paramers have curvilinear edges and the lobes are turned toward the inside with bristles in the apical area. The basal part holds the paramers together; these are joined around the median lobe towards half of its length (Fig. 19).

\section{VARIABILITY. Female unknown.}

DistRiBUtion. This new species is known only for the locus typicus: Togo, Sokodé, $400 \mathrm{~m}$ a.s.l.

DiFFERENTIAL DIAGNOSIS. In this species there are two main characters: the first is the general structure of the body and in particular the shape of the head with typical eyes and antennae similar to the species of the genus Pachymerus Thunberg 1805; the second is the presence of the preapical tooth in the posterior femurs, that distinguishes the species of the genus Bruchus Linnaeus 1767. This new species does not have similar species to which it can be related.

\section{CONCLUSIONS}

In this study, seven species of Bruchidae new to science are described: five of them belong to the genus Bruchidius, one to the genus Spermophagus and one to the new genus Protobruchus, here described. Five of these species are from the Mediterranean area, Bruchidius horshensis n. sp., Bruchidius lekefensis n. sp., Bruchidius salinaensis n. sp., Bruchidius bcharréensis n. sp., and Bruchidius samai n. sp.; one from East Africa, Spermophagus nicotrai n. sp. = Spermophagus sp. Zampetti, 1988; one from West Africa Protobruchus togoensis n. sp.

\section{ACKNOWLEDGEMENTS}

The Authors are grateful for their collaboration to Maurizio Gigli (Roma, Italy) for the photos, Phyllis Crolla (Rocchetta al Volturno, Italy) for the English revision, Pietro Lo Cascio (Lipari, Italy), Gianfranco Sama (Cesena, Italy) and Stefano Zoia (Milano, Italy) for the specimens that they so kindly gave us for this study.

\section{REFERENCES}

Allard E., 1868. Étude sur le groupe des Bruchites d'Europe et du bassin de la Mèditerrannèe. Annales de la Societe Entomologique Belge, 9: 82-124.

Bouchard P., Bousquet Y., Davies A.E., Alonso-Zarazaga M. A., Lawrence J.F., Lyal C.H.C., Newton, A.F., Reid C.A.M., Schmitt M., Slipinski S.A. \& Smith A.B.T., 2011. Family- group names in Coleoptera (Insecta). ZooKeys, 88: 1-972.

Johnson C. D. \& Kingsolver J. M., 1981. Checklist of the Bruchidae (Coleoptera) of Canada, United States, Mexico, Central America and the West Indies. Coleopterists Bulletin, 35: 409-422.

Migliaccio E. \& Zampetti M. F., 1989. Megabruchidius dorsalis e Acanthoscelides pallidipennis, specie nuove per la fauna italiana. (Coleoptera, Bruchidae). Bollettino dell'Associazione romana di entomologia, 43(1988): 63-69.

Pic M., 1902. Colèoptëres prèsumès nouveaux de la Rhodèsie. Revue Française d'Entomologie, 21: 4-7.

Pic M., 1903. Colèoptëres de l'Afrique australe. Revue Française d'Entomologie, 22: 165-171.

Pic M., 1904. Diagnoses de Colèoptëres Palaeractiques et exotiques. Echange, 20: 33-36.

Pic M., 1913a. Coleopterorum Catalogus. Bruchidae in "Junk-Schenkling: Coleopterorum Catalogus". 26: 174.

Pic M., 1913b. Colèoptëres exotique en partie nouveaux. Echange, 29: 106-110, 115-117; 142-144.

Pic M., 1913c. Descriptions de 29 espëces et de plesieurs variètès. Mélanges exotico-entomologiques, 5: 7-8.

Ricci M.S. \& Zampetti M.F., 2007. Contributo alla conoscenza dei bruchidi del Nord Africa e delle Isole Canarie (Coleoptera Bruchidae). Bollettino della Società entomologica italiana, 139: 43-57.

Ricci M.S. \& Zampetti M.F., 2005. Contributo alla conoscenza dei bruchidi dell'Europa (Coleoptera Bruchidae). Entomologica, 39: 121-167.

Southgate B.J., 1979. Biology of the Bruchidae. Annual Review of Entomology, 24: 449-473.

Yus-Ramos R., Kingsolver J.M. \& Nápoles J.R., 2007. Sobre el estatus taxonómico actual de los brúquidos (Coleoptera: Bruchidae) en los Chrysomeloidea. Dugesiana, 14: 1-21.

Yus-Ramos R., Ventura D., Bensusan K., Coello-García P., György Z. \& Stojanova A., 2014. Alien seed beetles (Coleoptera: Chrysomelidae: Bruchinae) in Europe. Zootaxa, 3826(3): 401-448.

Zampetti M.F. \& Ricci M.S., 2012. Guida ai Coleotteri Bruchidi della Fauna Italiana. Sistematica e biologia Gestione e controllo. Darwin Edizioni, Roma, 430 pp. 